\title{
Association Between Moral Distress and Job Satisfaction of Japanese Psychiatric Nurses
}

Asian/Pacific Island Nursing Journal

Volume 1(2): 55-60

(C)Author(s) 2016

http://digitalscholarship.unlv.edu/apin/

\author{
Michiyo Ando and Masashi Kawano ${ }^{\mathrm{b}}$
}

\begin{abstract}
Moral distress of psychiatric nurses may affect their job satisfaction or quality of nursing care, thus examination of their moral distress is a significant issue for practice. The purpose of this study was to investigate the level of moral distress and job satisfaction, and association between moral distress and job satisfaction. One hundred and thirty nurses who worked in psychiatric wards in a hospital in Japan completed the Moral Distress Scale for psychiatric nurses (MDS-P) and the Job Satisfaction scale (JS). The MDS-P consisted of subdomains such as "unethical conduct by caregivers," "low staffing," and "acquiescence to violations of patients' rights" in intensity and frequency; the JS consisted of seven subcategories. An institutional review board in the researcher's college approved this study. Results showed that the "acquiescence to violations of patients' rights" was the highest of the subdomains of MDS-P, and the "interactions among nurses" was the highest of the subdomains of the JS. The unethical conduct by caregivers (MDS-P) score was negatively correlated with administration (JS) for intensity $(r$ $=-.40, p<.001)$ and frequency $(r=.37, p<.001)$. Moreover "acquiescence to violations of patients' rights (MDSP)" was also negatively correlated with the "task requirement (JS)" score for intensity $(r=-0.49, p<.001)$ and for frequency $(r=-0.50, p<.001)$. These results suggest that reduction of moral distress increases job satisfaction particularly for administration and task requirement in nursing care.
\end{abstract}

Keywords: Japan, job satisfaction, moral distress, psychiatric nurse

In clinical situations, nurses experience various kinds of moral distress. Moral distress is defined as moral and ethical problems that "arise when one knows the right thing to do, but institutional constraints make it nearly impossible to pursue the right course of action (Jameton, 1984, p. 6). A previous study indicated that nurses feel moral distress (Whitehead, Herbertson, Hamric, Epstein, \& Fisher, 2015). Although there are a variety of different nursing situations, Japan has certain notable characteristics in psychiatric nursing environments.

The length of stay among psychiatric patients in Japan seems to be long. Data show that the duration of stay of Japanese patients was about 300 days, while the mean duration in other countries was under 50 days, and the number of beds occupied by psychiatric patients in Japan is higher than other countries as well (Organisation for Economic Cooperation and Development, 2012). According to the Ministry Health \& Labor (2014), the number of physicians and nurses working for each 100 beds in psychiatric wards in Japan is 3.6 and 21, respectively, compared to 15.3 and 54.3 in general wards. Therefore, the length of hospital stay for psychiatric patients in Japan is much longer than those in other countries. Also, there is a higher shortage of physicians and nurses in psychiatric wards compared to those in general wards. Although a patient's symptoms may be stable, many can't be discharged from the hospital because of a shortage of accommodations, shortage of work opportunities, and prejudice in living in the community. This tendency for a long-term stay of patients is one of the sources of moral distress for nurses in Japan.

Moral distress affects nurses in various aspects (Hamaideh, 2014; Ohnishi et al., 2011). It leads to symptoms such as emotional distress, grief to the point of anguish, and physical symptoms (McGibbon, Peter, \& Gallop, 2010). It also is associated with job

\footnotetext{
${ }^{a}$ Saint Mary's College, Kurume City, Fukuoka, Japan

${ }^{b}$ Arima Kogen Hospital, Japan

Corresponding Author:

Michiyo Ando, St. Mary's College, Kurume, Fukuoka, Japan

Phone: +81-942-50-0744

Email: andou@st-mary.ac.jp
} 
dissatisfaction, fatigue, and turnover (DeTienne, Agle, Phillips, \& Ingerson, 2012). In our previous study, we selected variables such as general health, sense of coherence, and job satisfaction as influencing moral distress (Ando \& Kawano, in press). We examined associations among these variables because either previous studies had not included them or some association was found. However, we did not examine the association between moral distress and job satisfaction including the subdomains in that study. Job satisfaction is an important factor for nurses to perform their work since job satisfaction has an impact on intentions to leave and turnover for hospital-based nurses (Coomber \& Barriball, 2007). de Veer, Francke, Struijs, and Willems (2013) showed that high moral distress levels were related to lower job satisfaction and some factors of job characteristics related to job satisfaction. However, they did not sufficiently explain the association between subdomains of moral distress and job satisfaction. If we can clarify these associations, we can make recommendations for improvements in the clinical situation. Moreover, although Ohnishi et al. (2010) found a high-level subcategory of moral distress, would the same results be obtained in another study? We hypothesized that there would be an association between moral distress and job satisfaction in some of the subdomains. Therefore, we examined levels of moral distress and job satisfaction and investigated the association between those variables.

\section{Methods}

\section{Research Design}

This study is a secondary data analysis of a previous study using a cross-sectional and correlational design. We hypothesized that moral distress may relate to job satisfaction of psychiatric nurses in Japan.

\section{Participants}

For sampling participants, we selected a convenience sample of nurses in hospitals in the middle of Japan. In Japan, there are differences in the number of beds in each province. In 2010, there were approximately 300 beds in use in this hospital. In sampling, the director of the nursing service department explained the study to head nurses and distributed the questionnaires to them in envelopes. An inclusion criterion was that participants had time to complete the survey, and an exclusion was that a participant did not have a serious mental disease.

The participants were nurses who worked at a national hospital in Japan. The total number of participants was 130 (male: 28, female: 102). They ranged in age between 20 to 69 years. The background of the participants is shown in Table 1 . The participants were mainly female $(78.5 \%)$ and the most common age range was 40 to 49 years old.

Table 1. Background of the Participants

\begin{tabular}{llcc}
\hline Item & & $\begin{array}{c}\text { Number } \\
(n=130)\end{array}$ & $\begin{array}{c}\text { Rate } \\
(\%)\end{array}$ \\
\hline Gender & Male & 28 & 21.5 \\
& Female & 102 & 78.5 \\
Age (years) & $20-29$ & 8 & 6.2 \\
& $30-39$ & 30 & 23.1 \\
& $40-49$ & 46 & 35.4 \\
& $50-59$ & 40 & 30.8 \\
Nursing experience & $60-69$ & 6 & 4.6 \\
(years) & & 18.7 & \\
Nursing experience & & 3.4 & \\
in current ward & & & \\
(years) & & 115 & 88.5 \\
Position & Staff & 15 & 11.5 \\
& Others \\
(chief, head & & \\
& nurse) & & \\
\hline
\end{tabular}

\section{Data Collection}

Ethical permission for this study was obtained from the institutional review board of St. Mary's College. The researcher contacted the director of the nursing service department in the hospital for permission for this study. Data collection was conducted in the hospital. The researcher distributed questionnaires to nurses in the hospital with the help of head nurses. The questionnaires were distributed in envelopes and included a cover letter explaining the study. Nurses who agreed to participate after reading the cover letter completed the questionnaires during their breaks or after work. The researcher or head nurses was not present while the nurses (participants) completed the questionnaires. After completion, the participants submitted the completed questionnaires in a designated box. Informed consent was implied by participants completing and submitting the questionnaire. The questionnaires were collected at a later date.

\section{Measurement}

Tools included the Moral Distress Scale-Psychiatry (MDS-P), Sense of Coherence (SOC), General Health Questionnaires (GHQ), and Job Satisfaction scale (JS). We analyzed the association between these variables in the previous study (Ando \& Kawano, in press). In the present study, we focused only on MDS$\mathrm{P}$ and $\mathrm{JS}$ as a secondary analysis and discuss the details as follows. 


\section{Moral Distress Scale-Psychiatry (MDS-P) Scale}

The MDS-P was developed by Ohnishi et al. (2010) based on the work of Corley, Elswick, Gorman, and Clor (2001). It is a Japanese version and includes three factors: 1) "unethical conduct by caregivers," which consists of six items describing direct involvement of caregivers in unethical conduct; 2) "low staffing," which consists of five items; and 3) "acquiescence to violations of patients' rights," which consists of four items. Internal consistency was determined by calculating Cronbach's alpha values, which were 0.90 for total MDS-P, 0.85 for Factor 1, 0.82 for Factor 2, and 0.79 for Factor 3 . These scores support the reliability of the MDS-P. The MDS-P uses a 7-point Likert format scale. Higher scores reflect more severe levels of distress: from 0 (one) to 6 (a great extent) for intensity, and from 0 (never) to 6 (very frequently) for frequency.

\section{Job Satisfaction (JS) Scale}

This scale was developed by Stamps, Piedmont, Slavitt, and Haase (1978). Ozaki and Tadamasa (1998) translated it into Japanese and we used the Japanese version. The scale includes 48 items and is divided into 7 subscales: 1) pay, 2) professional status, 3) doctor-nurse relationship, 4) administrative policies, 5) autonomy, 6) task requirements, and 7) interactions among nurses. Each item is scored on a Likert scale ranging from 0 (very strongly disagree) to 6 (very strongly agree). A higher JS score indicates that a nurse has greater job satisfaction and agrees that the subscale items are present in their current job. The reliability was confirmed by the correlation coefficient ( $r=0.87$ ) by the test-retest method. The validity was confirmed by the sentence completion method.

\section{Demographic Data}

Data for age, gender, years of nursing experience, years of nursing experience on the current ward, and position were also collected.

\section{Data Analysis}

The statistical package for social sciences, SPSS ver, 22, was used to analyze the data. Descriptive statistics were used to calculate the mean score and standard deviation. Since the MDS-P measured level of intensity and frequency of moral distress, we analyzed both. The strength and direction of the association between variables were determined using Pearson's correlations coefficients. Significance was set at .05. We used one-way ANOVA to clarify the level of moral distress and job satisfaction from subdomains of the scales.

\section{Results}

MDS-P and JS scores are shown in Table 2. Since the number of items in the subcategories is different, we also showed mean scores. Similarly, the one-way ANOVA was conducted on intensity and frequency scores of the MDS-P. For the intensity score, there was a significant difference among three domains $(F[2,38]=14.5, p<.001)$. The "acquiescence to violations of patients' rights" score was the highest of the three factors, followed by "unethical conduct by caregivers," and "low staffing." As for the frequency score, there was also significant differences among the three domains $(F[2,389]=38.7, p<.001)$. The order of high scores was the same as the intensity score: "acquiescence to violations of patients' rights," "unethical conduct by caregivers," and "low staffing."

Tables 2. The Total and Subdomain Scores of MDS-P and $J S(n=130)$

\begin{tabular}{|c|c|c|}
\hline \multirow{2}{*}{$\begin{array}{l}\text { Subcategories } \\
\text { MDS-P (intensity) total }\end{array}$} & Total sum & $M$ \\
\hline & $31.3 \pm 19$ & - \\
\hline $\begin{array}{l}\text { 1) Unethical conduct } \\
\text { by caregivers }\end{array}$ & $8.03 \pm 5.48$ & $2.00 \pm 1.37$ \\
\hline 2) Low staffing & $10.12 \pm 8.32$ & $1.69 \pm 1.39$ \\
\hline $\begin{array}{l}\text { 3) Acquiescence to vio- } \\
\text { lations of patients' } \\
\text { rights }\end{array}$ & $13.18 \pm 7.92$ & $2.64 \pm 1.58$ \\
\hline MDS-P (frequency) total & $27.2 \pm 16.8$ & - \\
\hline $\begin{array}{l}\text { 1) Unethical conduct } \\
\text { by caregivers }\end{array}$ & $7.21 \pm 5.04$ & $1.80 \pm 1.26$ \\
\hline 2) Low staffing & $7.95 \pm 7.21$ & $1.33 \pm 1.20$ \\
\hline $\begin{array}{l}\text { 3) Acquiescence to vio- } \\
\text { lations of patients' } \\
\text { rights }\end{array}$ & $12.1 \pm 7.33$ & $2.41 \pm 1.47$ \\
\hline JS total & $148.8 \pm 28.4$ & - \\
\hline 1) Salary & & $2.53 \pm 0.77$ \\
\hline 2) Professional status & & $3.37 \pm 0.83$ \\
\hline $\begin{array}{l}\text { 3) Doctor-nurse rela- } \\
\text { tionships }\end{array}$ & & $2.97 \pm 1.24$ \\
\hline 4) Administration & & $3.08 \pm 0.68$ \\
\hline 5) Autonomy & & $3.30 \pm 0.98$ \\
\hline 6) Task requirement & & $2.88 \pm 0.86$ \\
\hline $\begin{array}{l}\text { 7) Interactions among } \\
\text { nurses }\end{array}$ & & $3.62 \pm 0.84$ \\
\hline
\end{tabular}

A one-way ANOVA was conducted on JS scores. There was a significant difference in sub-domains of JS $(F=[1,124]=38.5, p<.001)$. The "interactions among nurses" (3.62) was the highest score. Next, "professional status" (3.37) and "autonomy" (3.3) were higher than other factors. The "pay" factor was the lowest in the JS. 
Relationships between the JS and the MDS$\mathrm{P}$, the total JS scores were significantly correlated with MDS-P (intensity: $r=.44, p<.001$; frequency: $r=$ $0.45, p<.001)$. There were significant correlations between subdomains of the MDS-P and JS (Table 3, Table 4). Results showed that the "unethical conduct by caregivers" (MDS-P) score negatively correlated with "administration n" (JS) for intensity $(r=-.40, p<.001)$ and frequency $(r=.37, p<.001)$. Moreover, "acquiescence to violations of patients' rights" (MDS-P) negatively correlated with the "task requirement" (JS) score for intensity $(r=-0.49, p<.001)$ and for frequency $(r=-0.50, p<.001)$.

Table 3. Correlation Coefficients Between JS Subcategories and MDS-P (Intensity)

\begin{tabular}{llll} 
& $\begin{array}{l}\text { Unethical conduct by care- } \\
\text { givers }\end{array}$ & Low staffing & $\begin{array}{l}\text { Acquiescence to violations } \\
\text { of patients' rights }\end{array}$ \\
\hline Pay & $-.30 * * *$ & $-.23 * *$ & $-.37 * * *$ \\
Professional status & $-.19 *$ & -.09 & $-.18 *$ \\
Doctor-nurse relationships & $-.24 * *$ & $-.19 *$ & $-.24 * *$ \\
Administration & $-.40 * * *$ & $-.20 *$ & $-.36 * * *$ \\
Autonomy & $-.39 * * *$ & $-.25 * *$ & $-.33 * * *$ \\
Task requirement & $-.23 * *$ & $-.25 * *$ & $-0.49 * * *$ \\
Interactions among nurses & $-.30 * * *$ & $-.27 * * *$ & $-.31 * * *$ \\
\hline
\end{tabular}

Note. ${ }^{*} p<.05, * * p<.01, * * * p<.001$

Table 4. Correlation Coefficients Between JS Subcategories and MDS-P (Frequency)

\begin{tabular}{|c|c|}
\hline $\begin{array}{l}\text { Unethical conduct by care- } \\
\text { givers }\end{array}$ & $\begin{array}{l}\text { Acquiescence to violation } \\
\text { of patients' rights }\end{array}$ \\
\hline
\end{tabular}

\begin{tabular}{llll}
\hline Pay & $-.26 * * *$ & $-.17 *$ & $-.38 * * *$ \\
Professional status & $-.21 * *$ & -.10 & $-.17 *$ \\
Doctor-nurse relationships & $-.30 * * *$ & $-.22 * *$ & $-.26 * * *$ \\
Administration & $-.37 * * *$ & -.13 & $-.35 * * *$ \\
Autonomy & $-.36 * * *$ & $-.24 * *$ & $-.32 * * *$ \\
Task requirement & $-.21 * *$ & $-.31 * * *$ & $-0.50 * * *$ \\
Interactions among nurses & $-.32 * * *$ & $-.28 * * *$ & $-.31 * * *$ \\
\hline
\end{tabular}

Note. ${ }^{*} p<.05, * * p<.01, * * * p<.001$

\section{Discussion}

The purpose of this study was to examine 1) level of moral distress and job satisfaction, and 2) the association between moral distress and job satisfaction, which are discussed below.

\section{Level of Moral Distress and Job Satisfaction}

For the MDS-P subdomains, "acquiescence to violations of patients' rights" score was the highest, followed by "unethical conduct by caregivers" and "low staffing." It shows that nurses feel high moral distress when they ignored rules in order to follow others, like physicians, in situations when patients received unnecessary tests or treatment or were given necessary tests or treatment without informed consent. This result is different than previous studies (Ohnishi et al., 2010; Ohnishi et al., 2012). In those studies, "low staffing" of the MDS-P was the most influential factor of the three subdomains. One explanation may be that the hospital in the present study was a national hospital and there was an adequate number of nurses. However, we need to examine the differences further. As for job satisfaction, the "interaction among nurses" was the highest followed by "professional status," "salary" was low. These results are supported by a previous study by Muya, Katsuyama, Ozaki, and Aoyama (2014) and similar among psychiatric wards and other wards in Japan.

\section{Correlations Analysis}

There was a significant correlation between total MDS-P and JS both in intensity and frequency. This may indicate that moral distress is related to job satisfaction and that resolution of moral distress may be important for the elevation of job satisfaction. Since the "quality of care for patients" is related to job satisfaction (Utriainen \& Kyngäs, 2009), and moral distress affects the quality of care for patients, these results may indicate a connection to job satisfaction. A 
similar result was found in a recent study in which moral distress was related to the intention of nurse practitioners in emergency departments to leave the practice (Trautmann, Epstein, Rovnyak, \& Snyder, 2015).

Subcategories in MDS-P and JS, the "unethical conduct by caregivers" was highly correlated with the "administration" score on JS. The factor "unethical conduct by caregivers" indicated that caregivers were directly involved in the unethical conduct, such as secretly mixing medication into patients' food. "Administration" in JS is about the order of work, policy of the institution, and participation in decisions of the institution. Thus, when nurses are involved in unethical conduct by caregivers, including themselves, according to rules, policies in the institution, or culture in it, they are dissatisfied with the administration. This association between "unethical conduct by caregivers" and "administration" is original in the present study. Reduction of moral distress related to administration such as "improvement of ethical climate" (Noh, Jung, \& Lee, 2013), "leadership style" (de Veer et al., 2013), and "organizations help to improve nurses' efficacy such that nurses raise their voice" (Rathert, May, \& Chung, 2016) may increase job satisfaction.

The MDS-P item "acquiescence to violations of patients' rights," which indicates where nurses either ignored or followed others such as physicians in situations where patients received unnecessary tests or treatment or were given necessary tests or treatment without informed consent, correlated with the JS item "task requirement." "Task requirement" means work where nurses have to act according to the rules, have to do nursing care for patients, or administrative work. That is, when nurses are involved in acquiescence to patients' right violations, they question whether their task is nursing care or not and they are dissatisfied with their task. In JS, the "professional status" domain score was high. Nurses who have professional consciousness question their tasks, which has an influence on job satisfaction. To cope with moral distress, nurses need to find ways to educate themselves and others about issues, and ways to support each other (Woods, 2014). Currently, in Japan, the Ministry Health \& Labor (2014) promotes the discharge of psychiatric patients whose symptoms are stable. Levels of moral distress may be changed when this policy is instituted.

\section{Conclusion}

Findings indicated that moral distress was correlated with job satisfaction. Improvement of unethical conduct by caregivers and acquiescence to patients' rights violations may increase job satisfaction in administration and task requirement in nursing care.

\section{Limitations}

A limitation was that the study was conducted in a hospital, so it cannot be generalized to other settings. Also, the hospital was a national hospital, so the result may not be the same in a private hospital. In future studies, we need to increase the sample size and setting to confirm the present findings.

\section{Acknowledgements}

We appreciate the nurses who participated in this study and also thank the administrators of each institution.

\section{References}

Ando, M., \& Kawano, M. (in press). The relationships among moral distress, sense of coherence, and job satisfaction of Japanese psychiatric Nurses. Nursing Ethics. doi:10.1016/j.apnu.2016.04.012

Coomber, B., \& Barriball, K. L. (2007) Impact of job satisfaction components on intent to leave and turnover for hospital-based nurses: A review of the research literature. International Journal of Nursing Studies, 44, 297-314. doi:10.1016/j.ijnurstu.2006.02.004

Corley, M. C., Elswick, R. K., Gorman, M., \& Clor, T. (2001). Development and evaluation of a moral distress scale. Journal of Advanced Nursing, 33(2), 250-256. doi:10.1046/j.1365-2648.2001.01658.x

de Veer, A. J. E., Francke, A. L., Struijs, A., \& Willems, D. L. (2013). Determinants of moral distress in daily nursing practice: A cross sectional correlational questionnaire survey. International Journal of Nursing Studies, 50, 100-108. doi:10.1016/j.ijnurstu.2012.08.017

DeTienne, K. B., Agle, B. R., Phillips, J. C., \& Ingerson, M. C. (2012). The impact of moral stress compared to other stresses on employee fatigue, job satisfaction and turn over: An empirical investigation. Journal of Business Ethics, 110, 377-391. doi:10.1007/s10551-011-1197-y

Hamaideh, S. H. (2014). Moral distress and its correlates among mental health nurses in Jordan. International Journal of Mental Health Nursing, 23, 33-41. doi:10.1111/inm. 12000

Jameton, A. (1984). Nursing practice: The ethical issues. New Jersey: New Prentice-Hall.

McGibbon, E., Peter, E., \& Gallop, R. (2010). An institutional ethnography of nurses' stress. Quality Health Research, 20, 1353-1378. doi:10.1177/1049732 310375435

Ministry Health \& Labor. (2014). Iryoshisetsucyosa byoin houkoku no gaikyo. Retrieved from http://www.mhlw. go.jp/toukei/saikin/hw/iryosd/14/

Muya, M., Katsuyama, K., Ozaki, F., \& Aoyama, H. (2014). Development of a scale measuring the job satisfaction of Japanese hospital nurses. Japan Journal of Nursing Science, 11, 160-170. doi:10.1111/jjns.12017 
Noh, Y. G., Jung, M. S., \& Lee, Y. S. (2013). Nurses' job satisfaction and organizational commitment according to hospital ethical climates types. Journal of Korean Academy of Nursing Administration, 19, 513-524. doi:10.11111/jkana.2013.19.4.513

Ohnishi, K., Kitaoka, K., Bowers, L., Stewart, D., Merwe, M. V. D., Nakano, M. ... Fujii, H. (2011). Comparison of moral distress and burnout experienced by mental health nurses in Japan and England: A cross-sectional questionnaire survey. Japan Health Medicine Association, 20, 73-86.

Ohnishi, K., Nakahara, J., Kitaoka, K., Nakano, M., Ohgushi, Y., Tanaka, H., \& Fujii, H. (2012). Comparison of moral distress experienced by psychiatric nurses in Japan and England: Measured by MDS-P. Japan Society of Nursing Research, 35(4), 101-107.

Ohnishi, K., Ohgushi, Y., Nakano, M., Fuji, H., Tanaka, H., Kitaoka, K., ... Narita, Y. (2010). Moral distress experienced by psychiatric nurses in Japan. Nursing Ethics, 17, 726-740. doi:10.1177/0969733010379178

Organisation for Economic Co-operation and Development. (2012). OECD Health Data 2012. Retrieved from http://www.oecd.org/els/health-systems/health-data.htm

Ozaki, G., \& Tadamasa, T. (1998). A study on the measurement of nurses' job satisfaction with their work situation in Japan: Trying to apply a questionnaire developed by Stampes and others [in Japanese]. Bulletin Osaka Prefecture College of Nursing, 10, 17-24.
Rathert, C., May, D. R., \& Chung, H. S. (2016). Nurse moral distress: A survey identifying predictors and potential interventions. International Journal of Nursing Studies, 53, 39-49. doi:10.1016/j.ijnurstu.2015.10.007

Stamps, P. L., Piedmont, E. B., Slavitt, D. B., \& Haase, A. M. (1978). Measurement of work satisfaction among health professionals. Medical Care, 16, 337-352. doi:10.1097/00005650-197804000-00006

Trautmann, J., Epstein, E., Rovnyak, V., \& Snyder, A. (2015). Relationships among moral distress, level of practice independence, and intent to leave of nurse practitioners in emergency departments: Results from a national survey, Advanced Emergency Nursing Journal, 37, 134-145. doi:10.1097/TME.0000000000000060

Utriainen, K., \& Kyngäs, H. (2009). Hospital nurses' job satisfaction: A literature review. Journal of Nursing Management, 17, 1002-1010. doi:10.1111/j.1365-2834. 2009.01028.x

Whitehead, P. B., Herbertson, R. K., Hamric, A. B., Epstein, E. G., \& Fisher, J. M. (2015). Moral distress among healthcare professionals: Report of an institution-wide survey. Nursing Scholarship, 47, 117-125. doi:10.1111/ jnu. 12115

Woods, M. (2014). Beyond moral distress: Preserving the ethical integrity of nurses. Nursing Ethics, 21, 127-128. doi:10.1177/0969733013512741 